\title{
Como pode o teatro contribuir para a ciência e vice-versa?
}

\section{Carl Djerassi}

A ciência no teatro é um tópico que pode assumir uma vasta dimensão, e que tem sido apresentado de dois modos muito diferentes, como se atesta em duas publicações recentes ${ }^{1}$. Contudo, num artigo com dimensões limitadas, como este, este tema só poderá ser tratado de maneira breve. Assim, opto por recorrer à minha própria experiência: enquanto químico, que, após meio século de pesquisa cujos resultados descrevo em mais de um milhar de artigos de literatura científica -, decidiu reinventar-se centrandose na literatura dita "verdadeira", que para efeitos deste artigo significa ficção e peças de teatro. As razões pessoais que motivaram a minha transformação de cientista em autor de ficção e drama não necessitam de explicação elaborada, na medida em que as descrevi num livro de memórias (2001). Ao invés, permitam-me que estreite ainda mais o meu foco de atenção recorrendo a quatro peças da minha autoria que estiveram ou estão em cena em Portugal como principais exemplos para a minha exposição. Na medida em que as minhas actividades de transposição da "ciência" para a literatura começaram com a ficção antes de entrarem no domínio do teatral, por outras palavras, movendo-se da página para o palco, permitam-me que proceda agora do mesmo modo.

\section{A química na literatura}

Não obstante a sólida evidência quantitativa, intuitivamente creio que a química é provavelmente a disciplina científica com menor representatividade na ficção ou no teatro em comparação com a medicina ou mesmo a física. De modo semelhante, apesar do facto de alguns dos mais famosos homens das letras, como Primo Levi ou Elias Canetti, terem sido igualmente químicos, creio que há muito menos autores-químicos na literatura do que cientistas com formação médica. Qual a razão?

Será porque os químicos empregam maioritariamente estruturas químicas, ao invés de se cingirem exclusivamente à palavra, sentindo deste modo dificuldade em comunicar mesmo no âmbito da sua especialidade, já para não falar do público em geral, sem o recurso a um quadro, a diapositivos ou a qualquer outro tipo de pictograma? Ou será porque os químicos se dedicam quase exclusivamente a abstracções de nivel molecular enquanto que os médicos passam os dias a ouvir as histórias de outros seres humanos? Afinal de contas, mesmo os romances ou peças de orientação mais científica alcançam um determinado nivel de sucesso, quando o alcançam, porque operam a um nivel humano. Por último, tenho que referir outro obstáculo que explica a razão pela qual muito poucos químicos escrevem peças. Desde a época de Galileu que grande parte do discurso formal escrito empregue pelos cientistas é monologista ou indirecto, ao passo que o teatro pertence ao universo do diálogo.

\section{Ciência-na-ficção}

0 que provocou em mim, um cientista de uma ciência dura, a química, a vontade de atravessar a fronteira da ficção e tornar-me um contrabandista intelectual? Um pouco tarde na vida, a meio da casa dos sessenta, decidi ajudar a estabelecer uma ponte no abismo cada vez mais profundo entre ciência e cultura popular de um modo pouco ortodoxo, e fazê-lo através de um género que apelido de "ciência-na-ficção" - que de modo algum deve ser confundido com ficção científica. Na minha opinião, um romance apenas pode ser designado de "ciência-naficção" se toda a descrição da ciência e dos comportamentos idiossincráticos dos cientistas nessa obra for real ou, pelo menos, plausivel. Nenhuma destas restrições se aplica à ficção científica. De maneira nenhuma estou a sugerir que os voos científicos da fantasia na ficção científica são inapropriados. Mas se alguém desejar efectivamente contrabandear factos científicos na imaginação de um público cientificamente iletrado - e creio mesmo que esse contrabando é benéfico intelectual e socialmente - então é crucial que os factos sejam descritos de modo exacto. Caso contrário, como poderá o leitor cientificamente não informado distinguir o que é apresentado como mero entretenimento e o que é conhecimento factual?

Mas de todas as formas literárias, porquê recorrer à ficção? A maior parte das pessoas sem educação científica temem a ciência, murmurando frequentemente: "Não compreendo a ciência," enquanto descem uma cortina mental no momento em que percebem que Ihes vão ser fornecidos dados científicos. É esse público - o leitor não científico ou até anti-científico - que quero cativar. Ao invés de começar com um preâmbulo agressivo, "deixemme que vos fale da minha ciência," prefiro iniciar de um modo mais inocente "deixem-me contar-vos uma história" e incorporar ciência real e cientistas verdadeiros na acção. Mas em vez de começar por descrever "que tipo" de investigação científica realizamos, gostaria de me centrar "no modo como" os cientistas se comportam. É é exactamente em relação a este ponto que um cientistatransformado-em-autor pode desempenhar um papel
ES. Zehelein, Science: Dramatic. Science Plays in America and Great Britain, 1990 - 2007, Heidelberg,

Universitätsverlag Winter 2009; K. Shepherd-Barr Science on Stage. From "Doctor Faustus" to "Copenhagen", Princeton, Princeton University Press, 2006.

Carl Djerassi

é autor, dramaturgo $e$ Professor Emérito de Química na Universidade de Stanford. É um dos poucos cientistas

americanos galardoado com o Prémio Naciona da Ciência pela primeira síntese química de um contraceptivo esteróide oral) e o Prémio Nacional de Tecnologia. Membro da Academia Nacional Americana das Ciências e da Royal Society (Londres), recebeu ainda 24 doutoramentos honoris causa e numerosos prémios. A sua obra publicada (contos, poemas, cinco romances, dez peças, bem como uma autobiografia e um livro de memórias) centra-se sobretudo em temas relacionados com a ciência e foi traduzida para dezassete línguas. Criou o Djerassi Resident Artists Program perto de Woodside, na Califórnia que tem oferecido espaço para residências e estúdios a mais de 2000 artistas das artes visuais, literatura, coreografia e música. 
particularmente importante, porque os cientistas operam no âmbito de uma cultura tribal cujas regras, hábitos e idiossincrasias geralmente não são transmitidas através de seminários ou livros específicos, mas são adquiridas através de um processo de osmose na relação mentordiscípulo. Para mim - enquanto homem da ciência tribal há mais de cinco décadas - é importante que o público não olhe para os cientistas como um grupo de totós, Frankenstein's ou Strangelove's. E porque a ciência-naficção não se refere apenas à ciência real, mas também a cientistas verdadeiros, sinto que um membro do mesmo clã será o melhor para descrever a cultura tribal do cientista e o seu comportamento. Como exemplo dos vários tópicos em que sinto conhecimento legítimo por detrás da cortina da ficção, permitam-me que mencione ao leitor o último romance, intitulado NO (1998), da minha tetralogia de ciência-na-ficção. Escolho-o porque demonstra a variedade de tópicos relacionados com a ciência que podem ser incorporados nas páginas de apenas um romance: a química do Óxido Nítrico, o seu papel biológico na erecção masculina, a sua comercialização através do estabelecimento e da operação de uma companhia típica de biotecnologia (com base no estudo de caso real em Silicon Valley), as lutas das mulheres na cultura científica, ainda dominada por homens, a crescente influência asiática na ciência americana, e finalmente o reaparecimento em NO de todos os personagens dos três romances anteriores. Apesar de parecer gabarolice, implica um cuidado atento.

0 desejo de utilizar os meus romances para introduzir furtivamente informação nas mentes dos inocentes leitores prende-se claramente com motivos didácticos e tem provavelmente origem no hábito inveterado de cientista, na medida que a escrita científica serve sobretudo como veículo de transmissão de informação. No entanto, a palavra "didáctica" é frequentemente pejorativa quando utilizada na ficção ou no teatro. Apesar deste aspecto, creio que Horácio, o poeta romano, justificou de modo persuasivo o seu uso judicioso na famosa fórmula da Ars Poetica: "Lectorem delectando pariterque monendo" [deleitar o leitor simultaneamente instruindo].

\section{Ciência-no-teatro}

Mas voltemo-nos novamente para o teatro, no sentido de argumentar que não é absolutamente fatal para um texto ser permeável a suaves toques de didactismo. Num livro recente (2008), expliquei porque é que o uso de diálogos sempre me interessou.

Uma das razões prende-se com a minha biografia. $\mathrm{Na}$ minha existência prévia como cientista durante um período de meio século, nunca me foi permitido, nem me dei ao luxo de permitir, usar o discurso directo nos meus textos. Com algumas raras excepções, os cientistas abandonaram completamente os diálogos desde o Renascimento, momento em que, especialmente na Itália, alguns dos mais importantes textos literários eram escritos na forma de diálogo - indo de registos expositivos, mais didácticos ou mais conversacionais ou satíricos - que atraiam tanto autores como leitores. Galileu é um extraordinário exemplo. E não era somente em Itália. Erasmo de Roterdão, por exemplo: os Colóquios são um maravilhoso exemplo de como as grandes mestres do Renascimento usaram o diálogo para tratar de temas tão variados como assuntos militares (Militaria), desporto (De Luso), cortejamento (Proci et puellae) ou sobre a juventude (Adolescentis et scorti). Esta explosão de escrita dialógica estimulou até estudos teóricos. Desde o século XVI a critica tentou sempre exaltar, defender, regular e - até - abolir este género de escrita, que é muitas vezes definido como "drama de armário" - teatro que se destina mais à leitura do que à representação.

Hoje em dia, o uso exclusivo do discurso directo é somente praticado na escrita dramática, sendo essa uma das razões pela qual escolhi essa via na minha actividade literária nos últimos doze anos. A ciência é intrinsecamente dramática - pelo menos, na opinião dos cientistas - mas quererá isto dizer que os cientistas são personagens dramáticas, ou que a ciência pode ser matéria de drama? Para mim, uma pergunta igualmente importante a colocar é: pode a ciência-no-teatro desempenhar um papel pedagógico em palco ou serão pedagogia e drama inconciliáveis? Será que o ímpeto de educar é um automático beijo da morte quando se escreve para o teatro comercial? Didáctico - que, em código, significa aborrecido - é normalmente o termo mais mortífero que um crítico pode usar para descrever uma peça.

Tal como já tive ocasião de constatar mais do que uma vez, muitas pessoas sem formação científica têm a firme convicção de que não serão capazes de compreender conceitos científicos, de modo que nem sequer tentam. Para um público deste género, são preferiveis os "casos históricos" a secas lições científicas. Estas são mais atractivas bem como um meio bem mais eficaz de suplantar os possiveis obstáculos. Se a narração destes "casoshistóricos" que involvam ciência ou cientistas for feita no palco e não numa tribuna ou numa página, então estamos a lidar com "ciência-no-teatro".

\section{Esse espermatozóide é meu! (An Immaculate Misconception)}

Para testar este argumento, escolhi como tópico para a 


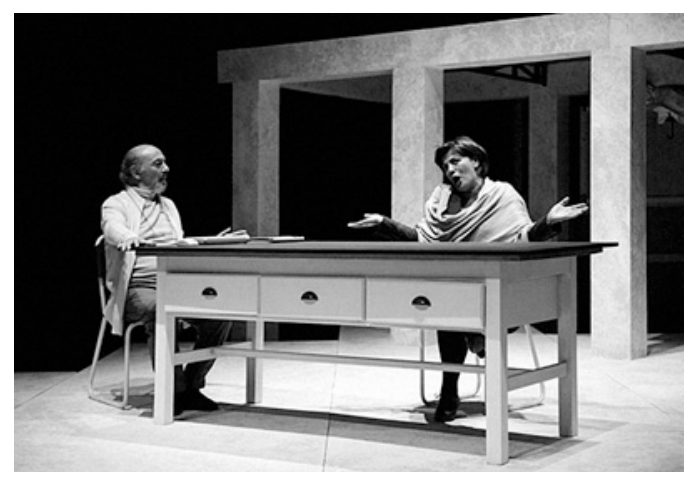

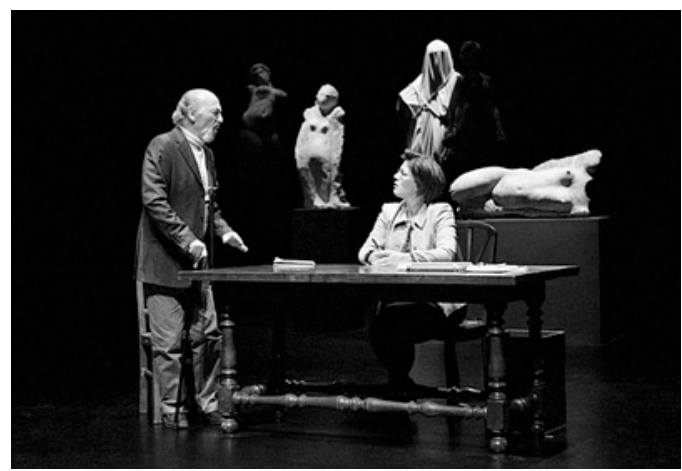

minha primeira peça, An Immaculate Misconception, a iminente separação entre sexo (na cama) e a fertilização (ao microscópio) uma vez que considero este tema um dos mais decisivos e fundamentais que a humanidade enfrenta neste século. Para a componente científica da minha peça, escolhi a tecnologia reprodutiva mais problemática (do ponto de vista ético), a ICSI (injecção intracitoplásmica de espermatozóides, ou seja, a inserção directa de um único espermatozóide no óvulo). Desconfio que poucos discordarão da ideia de que todos têm uma opinião sobre reprodução e sexo, e que a maior parte dos espectadores de teatro está convencido que conhece os factos da vida reprodutiva. Mas será que sabem mesmo? Aposto que poucos saberiam responder correctamente à seguinte questão: Uma vez que basta um único espermatozóide para fertilizar um óvulo, que quantidade de esperma tem um homem que ejacular de modo a ser considerado fértil? A resposta é: um homem fértil ejacula na ordem dos 50-100 milhões de espermatozóides durante a penetração; um homem que ejacule entre 1 a 3 milhões de espermatozóides - que até pode parecer um número considerável - é funcionalmente infértil. Há menos de 20 anos atrás não havia qualquer esperança para homens nestas condições. Mas hoje, muitos podem ser pais graças à ICSI. Contudo, quantos membros do público terão já ouvido falar da ICSI? Mas assim que tiverem assistido ao espectáculo, nunca mais se esquecerão.

0 sucesso relativo da minha primeira peça - traduzida já em 12 línguas (incluindo o português, apresentada em 2004, em Lisboa, no Teatro da Trindade, com o título Esse espermatozóide é meu! ${ }^{2}$ ) e transmitida pelo BBC World Service, NPR (EUA), WDR (Alemanha), e por rádios suecas e checas, bem como publicada em livro - pode em parte ser explicado à intemporalidade do tema e aos aspectos intrinsecamente dramáticos da reprodução humana que esta peça apresenta de uma maneira tão gráfica - um aspecto salientado em todas as críticas.

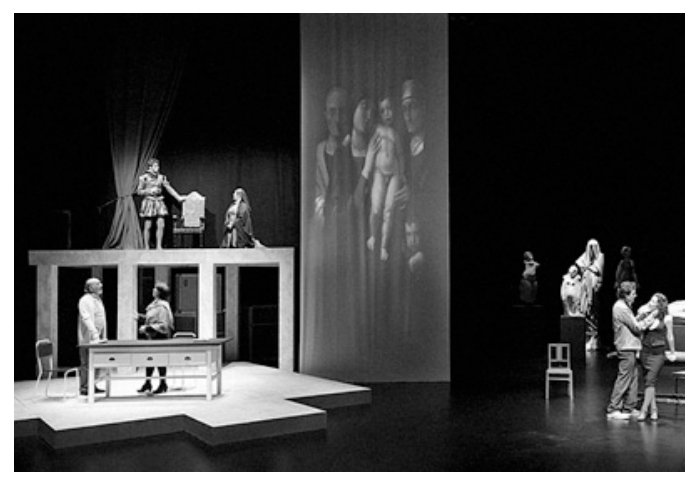

\section{Oxigénio (Oxygen)}

Mas sendo eu um químico que se torna dramaturgo, é para mim imperativo que a química seja apresentada cenicamente de uma maneira tão eficaz como, por exemplo, o sexo. Tive a sorte de encontrar um parceiro, Roald Hoffman, que se juntou a mim nesta experiência teatral. Em 1981, ele foi galardoado com o Prémio Nobel da Química pelas suas teorias. Mas, ao contrário do que acontece com muitos químicos, ele gosta de se relacionar com um público mais vasto, e tem-no feito através da sua poesia e dos seus escritos não-ficcionais. Tal como eu tentei esconder as minhas motivações didácticas atrás da cortina do sexo, em Oxigénio Hoffman e eu fizemos o mesmo escolhendo um tema - o Prémio Nobel - que, pelo menos para os cientistas, é potencialmente muito sexy. 0 ano de 2001 foi o centenário do Prémio Nobel; e é também o ano da acção da nossa peça.

Em Oxigénio postulamos que a Fundação Nobel decidiu celebrar o centenário estabelecendo um novo Prémio intitulado retro-Nobel, para "homenagear invenções ou descobertas feitas antes de 1901, o ano em que o primeiro Nobel foi entregue. Além de descrever dramaticamente a história da descoberta do oxigénio, a nossa peça tentava lidar com duas questões fundamentais: o que é a descoberta na ciência e porque é que é tão importante para um cientista ser o primeiro? Em Oxigénio, abordámos essas questões através dos encontros, discussões e escolhas do nosso Comité do Retro-Nobel. Esta é uma cena em que o presidente do Comité Retro-Nobel, Astrid Rosenqvist, debate a questão com os seus colegas masculinos:

ASTRID ROSENQVIS: Portanto, até agora temos: John Dalton, o pai da teoria atómica... Dimitri Ivanovitch Mendeleyev pela invenção da Tabela Periódica... August Kekulé pela estrutura do benzeno... e, claro, Louis Pasteur... Todos de primeira classe... e de diversas proveniências geográficas: um inglês, um russo, um alemão e um francês.

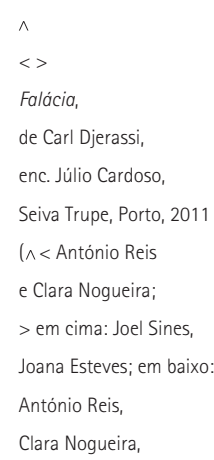
Jorge Loureiro e Joana Estrela), fot. António Alves. 
ULF SVANHOLM: E nenhum Americano, para variar!

ASTRID ROSENOVIST: É uma das vantagens em nos concentramos no século XIX. Todos concordamos que estes quatro são candidatos ao Retro-Nobel. Temos que reconhecer que foi com o primeiro que a quimica moderna começou.

SUNE KALLSTENIUS: Por outras palavras... com a descoberta do oxigénio.

ASTRID ROSENOVIST: Quem é que se oferece para escrever um pequeno parágrafo onde se explique ao público que sem a descoberta do oxigénio não haveria nenhuma revolução química... nem a química tal como a conhecemos hoje?

BENGT HJALMARSSON: Posso tentar. "Antes de Antoine Lavoisier

SUNE KALLSTENIUS: Queres dizer: "Antes de Carl Wilhelm Scheele

ULF SVANHOLM: E então o Joseph Priestley?

BENGT HJALMARSSON: E lá voltamos nós aos sarilhos habituais do Nobel! Demasiados candidatos.

Ao longo da peça, à medida que o Comité do Retro-Nobe debate a sua escolha, o público aprende alguma coisa sobre os três principais candidatos através de um triálogo durante uma adjudicação Real no que diz respeito às pretensões do farmacêutico sueco Carl Wilhelm Scheele (que primeiro o descobriu); o primeiro ministro-que-setorna-químico, Joseph Priestey (que primeiro o publicou) e o químico francês, economista e funcionário público, Antoine Laurent Lavoisier (que primeiro o compreendeu). Ao fazer o tempo oscilar pendularmente entre $2001 \mathrm{e}$ 1777, apresentamos o relato histórico e pessoal que vai levar o Comité do Prémio Nobel à sua decisão.

Até agora, Oxigénio já foi traduzida para 17 línguas (incluindo o português, e apresentada pela Seiva Trupe, no Teatro do Campo Alegre, no Porto ${ }^{3}$ ). 0 seu interesse
3 NT. Oxigénio - teatro cientifico, de Roald Hoffman e Carl Djerassi, trad. Manuel João Monte, enc. Júlio Cardoso, Seiva Trupe, 2006.

${ }^{4}$ NT. Apresentado a $17 \mathrm{de}$ Novembro, na Sala Carlos Ribeiro no Colégio de geral é demonstrado pelo facto de ter sido transmitida pela BBC World Service durante o centenário do Prémio Nobel (a 10 de Dezembro de 2001).

\section{Cálculo (Calculus)}

Cálculo, a terceira peça da minha trilogia "ciência-noteatro", já mereceu tradução para 5 línguas, incluindo o português (por Mário Montenegro) e será apresentada em Coimbra, em Novembro de 2011, pelo Marionet Theatre ${ }^{4}$. Nesta peça, quis abordar um tema que se presta particularmente bem ao teatro: a descrição do comportamento dos cientistas, ilustrando assim o "como" e não o "que" eles fazem. Quis expor as caracteristicas da cultura científica, a sua competitividade inerente, que no caso de dois dos mais famosos cientistas do século XVIII, Isaac Newton e Gottfried Leibnitz, se traduziu numa vendetta de 30 anos sobre quem teria realmente inventado o cálculo. 0 seguinte excerto ilustra o tom e a natureza da controvérsia:

LEIBNIZ: Sr. Newton, acusais-me de invadir território inglês? De roubar?

NEWTON: Chamai-Ihe o que quiserdes! Fui o primeiro a morder esta maçã... e espero comê-la a meu prazer.

LEIBNIZ: Uma maçã já mordida, especialmente uma inglesa, não me atrai. Necessito recordar-vos que, quando finalmente decidistes publicar o vosso "Método das Fluxões", anos após eu ter publicado, poucas pessoas o relacionaram com o meu "Cálculo Infinitesimal"? A vossa terminologia era um calão de pontos e linhas à deriva, os vossos "fluentes". E à sua taxa de variação... chamastes "fluxões". 0 vosso somar ou subtrair de pontos sobre as letras para representar (de forma ridicula) "fluxões de fluxões ou fluentes de fluentes" é a mais trapalhona das notações trapalhonas. (Vigorosamente). A minha era algébrica; a minha linguagem fresca e límpida usando as palavras "diferencial", "integral", e "função". Estas não encontro eu nos vossos escritos!

NEWTON: A minha questão é quem descobriu primeiro o método. A precedência é exclusiva. É um facto absoluto, quantificável.

LEIBNIZ: Quantificável?

NEWTON: Apenas um homem é o primeiro! Seja por anos, semanas, horas ou até minutos.

LEIBNIZ (Sarcástico): Isso não é levar a Matemática longe de mais?

\section{Falácia (Phallacy)}

Como exemplo final, tomarei a minha peça Falácia para demonstrar que fui além da pura ciência abordando também aspectos que se prendem com o cruzamento da ciência com outras disciplinas, tais como a Arte. Em Falácia uma historiadora (Regina) e um professor de química (Rex) discutem acerca da idade de uma estátua de bronze (historicamente documentada) que foi descoberta na Áustria no século XV e que até recentemente tem sido referida como a mais antiga estátua romana encontrada no norte da Itália - presumivelmente do séc. II. A peça foi traduzida, para português, por Manuel João Ponte e 


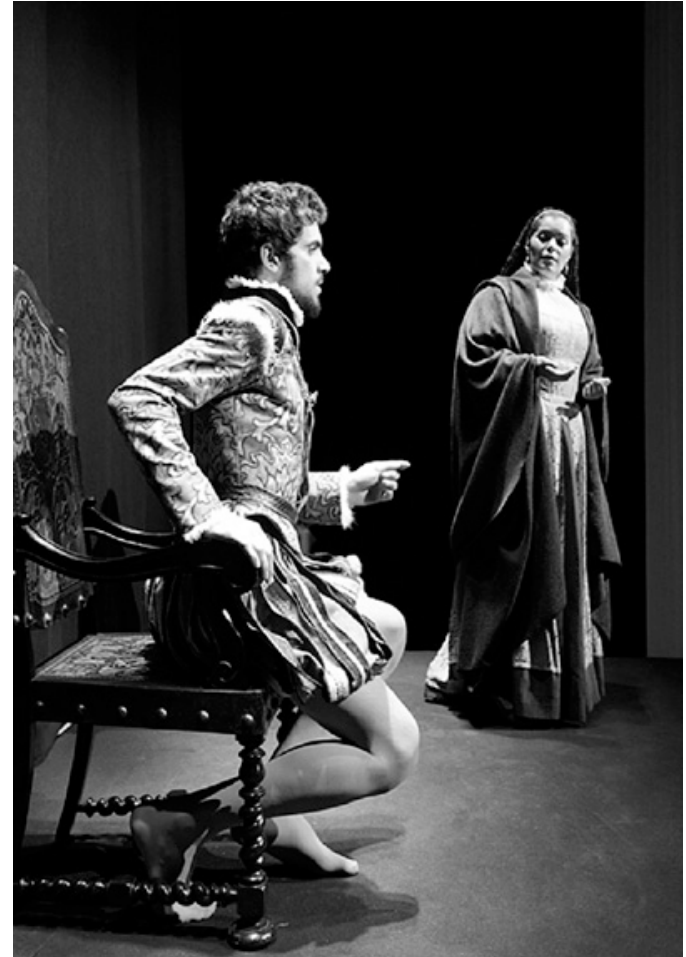

estreará em Outubro de 2011 com o título Falácia, pela Seiva Trupe. 0 seguinte excerto ilustra como um conflito prioritário - desta vez sobre disciplinas - pode ser sucintamente apresentado em palco:

REGINA: 0 que está a dizer é que a nossa escultura não pode ser de origem romana? Que todos os bronzes romanos, sem excepção, têm uma baixa percentagem de niquel?

REX: Digo que é extremamente raro. E é por isso que estou aqui. Por cortesia. Para lhe dizer... antes de informar qualquer outra pessoa... que estamos a desenvolver testes adicionais para provar a nossa suposição-

REGINA: Portanto, você está apenas a fazer uma suposição. Você assumiu que a escultura era um trabalho do Renascimento. Que toda as provas que apresento no meu livro... todas as 345 páginas... são lixo.

REX: Bem... disparate, não... eu não diria isso, não exactamente lixo-

REGINA: (Furiosa): Está a ver, é isto que eu acho tão irritante. Você seque obedientemente as regras da química que aprendeu enquanto estudante... e que agora ensina aos seus alunos... que as ensinarão aos alunos deles, isso é caca estéril-

REX: (Irritado): Caca?

REGINA: (Ignorando a interrupção): Eu disse caca "estéril"... consistindo em regras promovidas por saloios que odeiam arte, blindadas a qualquer sentido de beleza por um espesso nevoeiro espalhado entre uma orelha e outra. Você estripa qualquer vestigio de estética... ignora estilo, forma, patine... de facto todos os acessórios conotativos.

Alguém tinha realmente que picar esse seu balão cheio de arrogância farisaica... pomposa... simplista.

REX: Ainda irá lamentar essas palavras, senhora directora.

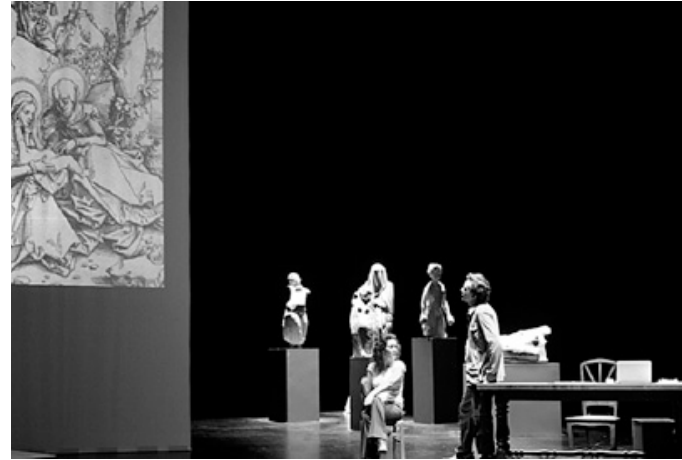

Falácia

de Carl Djerassi,

enc. Júlio Cardoso,

Seiva Trupe, Porto, 2011

$(<$ Joel Sines

e Joana Esteves:

$>$ Joana Estrela

e Jorge Loureiro),

fot. António Alves.

REGINA: (Ainda em ebulição): Transformando o vinho da estética em vinagre! Típico de vocês quimicos. Quando os quimicos chapinham na arte, o melhor que se poderá dizer é que os resultados são imprevisiveis.

REX: Imprevisibilidade é do que a ciência trata...

REGINA: Ai sim? E mesmo que assim seja, então porque não Ihe ensina humildade... em vez de arrogância? E porque não reconhecer a importância da beleza visual... um conceito que mal existe no seu mundo químico.

REX: Para esta discussão, a beleza da escultura não é importante. Nem mesmo a escultura é importante-

REGINA: Então o que é?

REX: A verdade

REGINA: E é tudo?

REX: É tudo.

REGINA: Que patético. E se a beleza desta escultura não é importante o que dizer da arte?

REX: Mas ela é mesmo necessária?

REGINA: A arte nunca é necessária. É apenas indispensável.

Peças científicas como obras científicas

Tal como mencionado anteriormente, estas quatro peças foram todas publicadas - facto que também se aplica a outras seis peças que escrevi. $E$ isto traz-me a um importante ponto com que desejo concluir.

Será que as peças contemporâneas se destinam a apresentações ocasionais em palco ou também merecem ser lidas como um outro livro qualquer? Ou, por outras palavras, destinam-se somente ao "Mostra, mas não contes" do palco ou também se prestam ao "conta, não te limites a mostrar" dos livros - algo que é geralmente feito pelas peças canónicas de grandes autores como Shakespeare, Schiller ou Molière? Acredito firmemente que alguns textos contemporâneos merecem essa dupla exposição. Mas a maior parte das peças são publicadas somente depois de serem estreadas em palco, normalmente por editores especializados, e não por editoras comerciais ou académicas. Além disso, o que ai é publicado é quase sempre o texto tal como foi representado, sem nenhumas alterações para a forma escrita. Isto levou-me a 
experimentar algo com a minha peça mais recente, Foreplay. E se começasse por escrever a peça a pensar somente no leitor, antes mesmo de contactar alguns teatros para saber se alguém estaria interessado em encená-la? Na eventualidade de haver interesse em montar o meu texto, procederia então às alterações necessárias para a sua versão de palco.

A experiência foi simples. Quando acabei Foreplay, no Verão de 2010, apresentei-a simultaneamente a três editores na Áustria, EUA e na Argentina, perguntando se estariam interessados em publicar o texto em tradução. Para minha surpresa, todos decidiram positivamente $e_{\text {, }}$ por coincidência, apontaram para que as traduções fossem lançadas em Março de 2011. Para mim, isto provou que não há editores não especializados em teatro, literários ou académicos que não acreditem que peças estilisticamente apropriadas ou intelectualmente desafiadoras não possam atrair leitores de uma maneira geral e não só espectadores. Pessoalmente, ficaria muitíssimo satisfeito se mais autores visassem esta "dupla publicação", de maneira a tornar a leitura de peças tão popular como o foram durante séculos os textos clássicos.

\section{Coda: Teatro vs. Cinema}

Poderíamos argumentar que, no que diz respeito a peças que lidam com a ciência, o cinema seria um meio melhor do que o teatro, uma vez que ai as ilustrações visuais são virtualmente ilimitadas, contrariamente ao que acontece no teatro - fisicamente limitado. Mas há, contudo, um ponto que é frequentemente menorizado ou esquecido. Um filme existe somente numa única versão - aquela que é distribuida - sendo que as únicas alterações são as que são feitas em virtude de legendagem ou dobragem. Assim, os filmes são congelados. No que diz respeito a um espectáculo de teatro, aplica-se o contrário. É vivo e, por

${ }^{5}$ A tradução dos excertos das peças Oxigénio e Falácia são da nossa responsabilidade; a de Cálculo cita a tradução portuguesa de Mário Montenegro. isso mesmo, nunca igual, mesmo quando representado pelos mesmos actores, no mesmo edifício, em noites sucessivas. Além da relação dinâmica entre público e actores, altera-se o tempo, os sentimentos inter-pessoais, e a qualidade da representação. Mas tomemos agora por exemplo uma peça representada em diversos países, teatros, e línguas. Então, podem ser feitas alterações pelo autor (se ainda estiver vivo), pelo encenador e, claro, pelos actores. Em An Immaculate Misconception, por exemplo, há apenas 3 personagens: uma mulher, bióloga reprodutiva; um médico e um físico nuclear. Na versão original, nos Estados Unidos, a bióloga e o médico são americanos e o físico é israelita. Em Singapura, a bióloga era chinesa e os dois homens ingleses expatriados. Em Lisboa, o físico era brasileiro e as outras duas personagens portuguesas. Estas alterações foram feitas por mim - mas imagine-se o leque de possibilidades que se podem abrir pela simples montagem de um texto num dado contexto e pela mão do encenador. Isso pode ser bem ilustrado nas imagens dos dois espectáculos a partir de Oxigénio - na cena em que se apresenta a descoberta do oxigénio ao Rei Gustavo da Suécia em 1777, tal como foi representada em 2009, em Seul, Coreia do Sul, e em 2010, no Teatro S. José, Costa Rica. Concluo afirmando que em termos de intimidade e possibilidade de variação, nada pode suplantar o teatro.

\section{Referências bibliográficas}

DJERASSI, Carl (1998), NO, Nona lorque, Penguin Books,

-- (2001), This Man's Pill: Reflections on the 50th birthday of the Pill, Oxford \&t Nova Iorque, Oxford University Press.

-- (2005), Falácia (trad. Manuel João Monte), Porto, Editora da Universidade do Porto.

-- (2008), Four Jews on Parnassus-a Conversation, Nova lorque, Columbia University Press.

-- (2011a), Foreplay, Madison, University of Wisconsin Press.

-- (2011b), Vorspiel (trad. Ursula-Maria Mössner), Innsbruck \& Vienna, Haymon Verlag.

-- (2011c), Preludio: Una historia de sexo en la Escuela de Frankfurt (trad. Cecilia Absatsz), Buenos Aires, Capital Intelectual.

DJERASSI, C., \& HOFFMANN, R. (2004), Oxigénio (trad. Juergen Heinrich Maar), Rio de Janeiro Vieira \&t Lent Casa Editorial.

-- (2005), Oxigénio (trad. Manuel João Monte), Porto, Editora da Universidade do Porto.

DJERASSI, C., Et PINNER, D. (2003), Newton's Darkness: Two dramatic Views, Londres, World Scientific Publ.-Imperial College Press.

Tradução Ana Raquel Fernandes e Rui Pina Coelho ${ }^{5}$ 